\title{
Educación en crisis
}

\section{Graciela Mazorco Irureta*}

\begin{abstract}
Resumen: Las reformas educativas unesconianas fracasaron. Las pedagogías constructivistas no generaron aprendizajes de mejor calidad al no romper la contradicción sujeto-objeto y no superaron las limitaciones del conductismo positivista. Para asumir el desafío del cambio epistemológico sin caer en el "nada cambia” del constructivismo, es necesario superar las limitaciones de la civilización antropocéntrica: sólo renunciando al antropocentrismo el individuo podrá sentirse humano al mismo tiempo que árbol, estrella, río o luciérnaga, y aprenderá de ellos lo que tengan que decirle. Para escucharlos y sentirlos, abrirá mucho más que sus sentidos y su mente; despertará las potencias finitas e infinitas que duermen en sus genes desde que el ser humano integral originario fue domesticado por la racionalidad educativa y comunicacional del sistema de la no unidad.

Palabras clave: educación, autopoiesis, acoplamiento-estructural, complementación, equilibrio, identidad, consenso
\end{abstract}

\section{Education in crisis}

\begin{abstract}
Education reforms of UNESCO failed. Constructivist pedagogies did not generate better learning to avoid breaking the contradiction of subject and object, and did not exceed the limitations of the positivist behaviorism. To meet the challenge of epistemological change without falling into constructivism's "nothing changes", it is necessary to overcome the constraints of civilization anthropocentric: only by renouncing anthropocentrism the individual may be able to feel human as well as tree, star, river or firefly, and will learn from them what they have to say to him. To hear and feel them, he will open much more than his senses and mind, he will awaken the finite and infinite powers who sleep on his genes since the originary integral human being was domesticated by the educational and communicative rationality of the non-unity system.
\end{abstract}

Key words: education, autopoiesis, structural coupling, complementarity, balance, identity, consensus

\section{Educação em crise}

Resumo: As reformas educacionais da UNESCO falharam. Pedagogias construtivistas não geraram uma melhor aprendizagem para evitar a ruptura da contradição entre sujeito e objeto e não ultrapassaram as limitações do behaviorismo positivista. Para enfrentar o desafio da mudança epistemológica sem cair em o nada muda do construtivismo, é necessário superar as restrições da civilização antropocêntrica: só renunciando ao antropocentrismo o indivíduo podera sentir o humano, enquanto árvore, estrela, rio ou vaga-lume, e aprender com o que eles têm a dizer. Para ouvir e sentir-se muito mais aberto aos seus sentidos e seu mente,

* Universidad Mayor de San Simón, Cochabamba, Bolivia. Email: gramaz@faces.umss.edu.bo 
despertar os poderes finito eo infinito que dormem em seus genes desde que todo o ser humano original foi domesticada pela racionalidade comunicativa do ensino e do sistema da não-unidade.

Palavras-chave: educação, autopoiese, acoplamento estrutural, complementaridade, equilíbrio, da identidade, do consenso

Recibido: 29.01.2010

Aceptado: 25.02.2010

$* * *$

\section{Introducción}

La crisis de la educación es estructural: pedagógica, epistemológica, socio-política y mucho más; es también ontológica, con lo cual se pone en juego la vigencia del paradigma básico o visión de mundo de una sociedadcivilización estructurada en torno a la separación hombre-mundo, al antropocentrismo y la jerarquía.

Es la crisis de una educación racionalista que no puede revertir la irracionalidad de una humanidad que ha llegado al límite de la creatividad que es posible haciendo uso exclusivo de las potencias del pensamiento abstracto. De ahí que las variadas reformas educativas promovidas por la UNESCO con un molde constructivista, y llevadas a cabo desde los ochenta en Latinoamérica, han resultado un fracaso.

Nuestra hipótesis es que esta crisis educativa es la expresión de un sistema civilizacional que ha perdido su creatividad para enfrentar sus tantas crisis cíclicas, de las que, hasta ahora, salía fortalecido gracias a ingeniosas maniobras de ajuste estructural en los ámbitos económicos, financieros, jurídicos y educativos. La última de ellas fue el neoliberalismo económico, ligado, en el ámbito educativo, con el modelo constructivista, cuyo método: el aprender a aprender, aparece, como otro fundamentalismo cognitivo frente al fracasado conductismo ${ }^{1}$ de corte positivista, criticado por su estilo manipulador de conductas, formador de sujetos reproductivos, acríticos, pasivos y disciplinados que siguen la lógica de la reproducción del sistema que los domina. Sin embargo, bajo su tónica subjetivista y liberadora, el constructivismo ${ }^{2}$ es también tecnocrático y responde al modelo de ser humano que mejor se ajusta al modelo neoliberal, que requiere individuos competitivos, productivos, reflexivos, autónomos y

\footnotetext{
${ }^{1}$ En el modelo pedagógico conductista, el sujeto es pasivo y reproductivo y el aprendizaje se considera una copia fiel de la realidad, obtenido por memorización y repetición acrítica de contenidos.

${ }^{2}$ El modelo pedagógico constructivista concibe que la educación tiene la finalidad de promover el desarrollo cognitivo de los seres humanos, estimulando la capacidad de pensamiento lógico, abstracto e hipotético-deductivo. De ese modo, el educando estará habilitado para "aprender a aprender" y se volverá un individuo independiente y autónomo en la adquisición (o auto construcción) continua del conocimiento (Mazorco 2003).
} 
autodeterminados, que sean emprendedores y autogestionen su individualidad. De ese modo, el Estado neoliberal puede desentenderse de su responsabilidad por la provisión de bienes y servicios de educación, salud, seguridad, pensiones, seguros, etc., reduciendo con ello el gasto social en forma sustantiva. En definitiva, la supuesta autodeterminación personal que se pretende en tiempos del neoliberalismo no significa más que una forma de control más económica del individuo, porque él mismo se autocontrola, mientras cree que está ejerciendo su soberanía individual.

La urgencia de un cambio paradigmático en la educación en la era global traspasa con mucho las usuales necesidades del sistema capitalista de reformatear al ser humano para ajustarlo a las demandas del crecimiento económico. Mucho más que eso, son las mismas probabilidades de supervivencia de lo humano como especie las que están comprometidas. La irrespetuosa osadía del hombre antropocéntrico lo ha llevado a manipular la naturaleza sin ningún sentimiento de complementación equilibrada, consensual y respetuosa de la identidad de cada elemento de la totalidad, hasta el punto en que están comprometidos los equilibrios que sostienen, no la supervivencia del planeta, sino la continuidad biológica de lo humano.

En ese sentido, nuestra crítica y propuesta transformadora apunta al cambio civilizacional que se erija sobre nuevos paradigmas ontológicos y epistemológicos -provenientes de la ciencia occidental complementariamente con la sabiduría originaria- que nos permitan recuperar la unidad ancestral entre el hombre y la naturaleza, en cuyo propósito la educación del nuevo tipo cumple un rol fundamental para deconstruir la alienación y domesticación a que nos ha sometido el sistema educativo occidental, y simultáneamente construir el ser humano integral no antropocéntrico, es decir: humano, natural, cósmico y total, capaz de autodeterminar su destino en equilibrio, complementariedad y consenso con todos los demás seres humanos, naturales y cósmicos de la realidad total, con pleno respeto a la identidad de cada otro y de sí mismo.

\section{Nuevos fundamentos epistemológicos del conocimiento: su base biológica}

El modelo conceptual de la civilización occidental considera que el mundo es objetivamente cognoscible a partir de la razón, mediante la aplicación del método científico como único modo de tener conocimiento de la realidad. Sin embargo, algunos pensadores de la postmodernidad han desafiado la pretensión homogeneizante de la ciencia, que descalifica como pre-científicos otros conocimientos y saberes marginalizados y sometidos “[...] en nombre del conocimiento verdadero y de los derechos de una ciencia que está detentada por unos pocos. Cambiar esta ideología vivida a través de la espesa capa institucional en la que se ha investido, cristalizado, reproducido [requiere] renunciar a la teoría y a los discursos generales [...] y hacer entrar en juego los saberes locales” (Foucault 1980: 39, 42,130). 
Un grupo de científicos denominado "Lindisfarne Fellows" (Miembros de Lindisfarne) compuesto por W. Thompson, G. Bateson, J. Lovelock, L. Margulis, H. Atlan, H. Maturana, F. Varela, H. Henderson, J. Todd y otros, desde 1981 ha estado compartiendo inquietudes intelectuales y uniendo diversos campos disciplinarios que abarcan la física, la astrofísica, la física cuántica, la genética, la química, la biología, etc. Su pensamiento está registrado en un encantador texto que elaboraron todos juntos y que invitamos a leer: Gaia: Implicaciones de la nueva biología. Ellos no tienen prejuicios en reconocer las limitaciones de la ciencia y en proponer la necesidad de revalorizar los conocimientos desprestigiados y calificados por la misma ciencia como mitos. Consideran que la relación entre el mito y la ciencia se está reformulando y que los hechos en que la que ésta funda el conocimiento pueden resultar más ingenuos que la imaginación, la intuición, los agudos poderes de observación y la sensibilidad que caracterizan a los individuos pertenecientes a las llamadas culturas precientíficas, quienes lograron, a diferencia de occidente, una complementación equilibrada con la biosfera (Thompson 1992).

Entre estos aportes nos interesa rescatar uno que está muy ligado a la propuesta de unidad entre mente y cuerpo, entre lo racional y lo no racional, que proviene de Humberto Maturana y Francisco Varela, representando un cambio de paradigma que rompe con el mecanicismo cartesiano y se acerca al pensamiento-sentimiento-vivencia originarios que conciben la realidad como una totalidad unitaria. Señalan un camino que podemos tomar para que la educación se vuelva un instrumento para la transformación social y la emancipación del individuo.

Durante los años setenta, el neurocientífico chileno Humberto Maturana, incursionando en el campo de la biología en equipo con su colaborador y ex-alumno de la Universidad de Chile, Francisco Varela, contribuyó a esclarecer la unidad mente-cuerpo, describiendo al conocimiento y al aprendizaje como fenómenos puramente biológicos, integradores no sólo de toda la contextura orgánica del individuo, sino también del medio. Los conceptos de organización de los seres vivos (su autopoiesis) y de adaptación permanente a través de su complementariedad con el medio (el acoplamiento estructural) son los fundamentos materialistas que utilizan Maturana y Varela para describir el conocimiento como proceso de vida ("vivir es conocer") en la que el ser-hacer-saber-sentir son una misma cosa en el desenvolvimiento de la existencia (Maturana y Varela 1995).

El acoplamiento estructural implica que un organismo y su medio están armónicamente conectados en un proceso de permanente y mutuo cambio complementario (Ibíd.). Existe una adaptación continua entre una unidad y su entorno, tal que la unidad experimenta continuos cambios estructurales para adecuarse a un medio que también está cambiando. Pese al permanente cambio mutuo en sus respectivas estructuras, se mantiene invariable la identidad de cada uno, así como la coherencia entre ambos (Maturana 1992). La autopoiesis es definida por estos autores como la for- 
ma de auto-organización de los seres vivos y significa que cada componente de un organismo es producido por otros componentes del mismo. Cada organismo se autogenera: se realiza y especifica a sí mismo, operación que se da en un círculo cerrado, sin poder diferenciarse entre productor y producto, entre inputs y ouputs, entre comienzo y final. El ser y el hacer son una misma cosa.

Esta cualidad de los seres vivos, sean o no humanos, define su autonomía, aunque ésta no es una cualidad exclusiva de los seres vivos (Maturana y Varela 1995) y hace de la vida un proceso de autocreación (Varela 1988). Es posible que los multicelulares sean el fruto de una simbiosis de unidades originariamente autónomas, es decir, de células que han interactuado para formar nuevas unidades autónomas ${ }^{3}$. "El fenómeno básico es, en todos estos casos, el mismo: elementos de diversos planos se reúnen operacionalmente y forman una unidad a raíz de su interacción circular. La autonomía nace en esta intersección” (Ibíd: 57).

El concepto de autonomía se contrapone a la instrucción y el control de las conductas -lo cual fue el centro del desarrollo tecnológico y vino de la mano con la cibernética y las teorías del control (Varela 1988)-, y equivale a negar el determinismo externo para reconocer, en cambio, un determinismo interno o autodeterminación. Los cambios estructurales que se operan en un organismo por su interacción con el medio no vienen determinados o especificados por el agente perturbante externo. Éste solo puede "modular el constante ir y venir de los balances internos", es decir: detonar. Pero lo que sucede en la unidad como consecuencia de ello es determinado por la propia unidad, por su estructura, por su propia dinámica. Las múltiples interacciones e interdependencias hacen que, cuando una dimensión es afectada, ello arrastra a todo el organismo a actuar con clausura operacional, esto es, como una red cerrada de cambios simultáneos en otros componentes y dimensiones, de manera circular. Como un efecto cascada, los cambios generan cambios en la red autopoiética para asegurar el equilibrio de la dinámica interna, haciendo que, frente a las continuas perturbaciones del entorno, se mantengan invariables ciertas relaciones entre los componentes de la unidad (Maturana y Varela 1995).

Nos interesa mostrar en este punto el acercamiento que existe entre los conceptos científicos de autopoiesis, acoplamiento estructural y auto-

\footnotetext{
${ }^{3}$ La combinación por complementación en la naturaleza, antes que la competencia en la que gana el más fuerte, aparece como la clave del proceso evolutivo. La combinación ha operado en algunos casos como simbiosis, en la que varias células se fusionan, conformando una unidad de segundo orden, de la cual las células originales aparecen como organelos. En otros se da sin fusión, como agregamiento de células que conforman un metacelular, en el que cada célula original mantiene sus límites individuales. La reproducción de algunos organismos multicelulares se da por fusión de una célula de un organismo (el espermio) con otra célula de otro organismo de la misma clase; ambas se fusionan, conformando el zigoto: una célula a partir de la cual se genera un nuevo organismo multicelular (Maturana y Varela 1995).
} 
nomía, y los principios de la teoría de unidad ancestral ${ }^{4}$, según la cual todo en la realidad está unido con todo, donde cada elemento contiene y es la misma realidad total. Desde esa óptica, todo se complementa por combinación e intracombinación, en equilibrio, complementación, consenso y respeto a la identidad propia y del otro.

En términos de Gonzáles e Illescas (2002): por la combinación e intracombinación de la realidad, todos los elementos se complementan (es el acoplamiento estructural), no sólo por la inter-relación, que supone una acción de intercambio en un sólo sentido, o de ida y vuelta, sino además, por la intra-relación. En la inter-relación, el otro penetra, y en el propio uno, hacia el interior y sin etapas sucesivas, se da la intracombinación (o clausura operacional en términos de Maturana y Varela), en la que el metabolismo asimila o desasimila lo interpenetrado, según le convenga, o no, al pleno desenvolvimiento de su propio potencial; se alcanza así, con autonomía, la permanente autogeneración (los científicos chilenos dicen: autopoiesis) de cada elemento. De manera similar, Maturana y Varela (1995) describieron que cuando una unidad es afectada por perturbaciones externas (podríamos decir en términos de la unidad: cuando realiza una combinación por inter-relación), ella misma auto-desencadena en su interior una serie de cambios que le aseguran mantener los balances (equilibrios) internos correlativos (esto equivale a realizar la intracombinación), y hace posible así preservar la organización autopoiética (autogenerada) del organismo.

\section{Unidad mente-cuerpo: el ser-hacer-saber-sentir}

“La cognición es proceso de vida que incluye percepciones, emociones y comportamiento, y no implica transferencia de información ni representaciones mentales” (Capra 1998: 295). El concepto de auto-organización ya no permite visualizar al cerebro como un procesador de información y examina a la cognición como el proceso de vida: vivir es conocer o, como dice Capra (Ibíd.:277, 300): "Los sistemas vivos son sistemas cognitivos. [...] El conocimiento del entorno es propiedad común de todos los niveles de vida”.

La manera cibernética ${ }^{5}$ de tratar el fenómeno del conocimiento “como si hubiera hechos u objetos allá afuera que uno capta y se los mete en la cabeza” ya no es viable, dicen Maturana y Varela (1995), debido a

\footnotetext{
${ }^{4}$ Elaboramos esta propuesta teórica, elaborada por el amauta inca José Illescas y Tatiana Gonzáles, en: Filosofía, Ciencia y Saber Andino, texto de Graciela Mazorco publicado en Bolivia (2007) por la Universidad Mayor de San Simón, y en Chile, por la Editorial Universidad Bolivariana, Santiago, en el año 2008.

${ }^{5}$ La cibernética definió el conocimiento como una representación mental de un mundo externo e independiente, y al cerebro como una computadora que capta información del medio para elaborar representaciones del mundo, en base a las cuales puede adoptar una conducta acorde para la vida.
} 
que no existe ningún mecanismo biológico que permita tal captación de información y porque implica un determinismo externo que contradice la auto-organización aupoiética de los seres vivos.

Adicionalmente, la conducta no es privativa de los organismos con cerebro. Con o sin sistema nervioso los seres vivos manifiestan conductas complementarias con el medio ${ }^{6}$, autodefiniendo una serie de cambios de estado para adaptarse a él. El observador adjudica a estos cambios de estado, siempre que sean visibles externamente (y no siempre lo son), el nombre de conducta, y dirá que hay aprendizaje cuando el observador encuentre que la conducta del organismo se adapta a los cambios del medio. De ese modo, lo que el observador define como conducta adecuada depende de sus propias expectativas; será adecuada una conducta observada en la medida en que los cambios de estado sean aquellos esperados por el observador y calificados por él como apropiados. No obstante, para el organismo sólo hay acoplamiento estructural, y además siempre lo hay: mientras el organismo esté vivo no hay posibilidad de que un cambio de estado no sea adecuado a los cambios del entorno (Maturana y Varela 1995).

El hecho de vivir es una función cognitiva y todos los seres vivos realizan la cognición. La vida es un eterno proceso de ser-hacer ininterrumpidamente el acoplamiento estructural con el medio, que se expresa en una conducta adaptativa; por tanto, vivir es conocer: el ser-hacer-saber son una unidad (Maturana y Varela 1995).

Este proceso vital de conocer involucra a todo el organismo (sistema nervioso, sistema endocrino y sistema inmunológico), aunque no es siquiera necesaria la presencia del sistema nervioso ni del cerebro para hablar de conocimiento. Esta apreciación responde a una nueva visión de la mente, elaborada tanto por Maturana como por Gregory Bateson, aunque en forma separada. Este último planteó la unidad mente-naturaleza; reconoció que la mente es la esencia de estar vivo y sostuvo que el proceso mental es un sistema que involucra el aprendizaje, la memorización y la toma de decisiones, aunque no haya cerebro y, más aún, se manifiesta no sólo en organismos individuales, sino también en comunidades naturales (ecosistemas) y sociales (Capra 1998).

Maturana y Varela manifiestan que el cerebro no es necesario para que exista la mente. Toda célula y todo organismo, sea planta o animal uni o multicelular, realizan su adaptación al entorno, la cual se identifica como una actividad inteligente, cognitiva o mental, aún en ausencia de sistema nervioso ${ }^{7}$ y de cerebro ${ }^{8}$.

6 "Lo que hace la presencia del sistema nervioso, es expandir el dominio de posibles conductas al dotar al organismo de una estructura tremendamente versátil y plástica” (Maturana y Varela 1995: 92).

${ }^{7} \mathrm{El}$ sistema nervioso se desarrolla en los multicelulares como modo de poner en contacto las células sensoriales con las células motoras (ambas distribuidas por diferentes partes del cuerpo), por medio de las neuronas (la red de interconexiones neuronales que constituye el 
Investigaciones recientes en las que está involucrado, entre otros, Francisco Varela, revelan que en la cognición no interviene solamente el cerebro (Capra 1998); también lo están el sistema inmunológico y el endocrino. Candace Pert, neurocientífica del instituto de Salud Mental de Maryland, denuncia que: "El sistema nervioso no está estructurado jerárquicamente, de modo que no se puede distinguir claramente entre el cerebro y el resto del cuerpo. Por ejemplo: los glóbulos blancos son partes de cerebro que flotan por el cuerpo” (Capra 1998: 292-4).

Los tres sistemas nervioso, inmunológico y endocrino se conciben hoy como complementarios. Están interconectados por los péptidos ${ }^{9}$ : macromoléculas que operan como mensajeros moleculares y se ligan a los receptores específicos que existen en la superficie de todas las células del cuerpo; de esa manera interconectan las células inmunológicas (los glóbulos blancos), las glándulas del sistema endocrino y el cerebro. Lo que se creía que eran hormonas producidas por ciertas glándulas, ahora se identifica como péptidos, que también produce y almacena el cerebro. Al mismo tiempo, se ha descubierto que las endorfinas, unos neurotransmisores producidos por el cerebro, son también producidos por las células del sistema inmunológico. O sea que los péptidos son producidos por las células nerviosas, por los glóbulos blancos (sistema inmunológico) y por las glándulas del sistema endocrino (Capra 1998). De hecho, Varela considera “a los sistemas nervioso e inmunológico como dos sistemas cognitivos interactivos, dos «cerebros» en constante diálogo" (Ibíd.: 291). Si a eso añadimos la nueva teoría, sustentada, entre otros, por Michael D. Gershon, jefe del Departamento de Anatomía y Biología celular de la Universidad de Columbia, en Nueva York, de que el estómago es un segundo cerebro ${ }^{10}$, tenemos que, además del sistema nervioso, inmunológico y endocrino, está involucrado el sistema digestivo en el proceso que une la mente y el cuerpo en el conocer.

sistema nervioso). En cambio en las bacterias, al ser unicelulares, la superficie sensoria y la motora son la misma; no necesitan intermediario que las conecte. Por su parte, las plantas carecen de células motoras y, por tanto, de sistema nervioso; por ello, el acoplamiento estructural, que se traduce en cambios de forma, pero no en movimiento, no es asociado tradicionalmente con el concepto de conducta. No obstante, los cambios de forma deben ser considerados como conducta adaptativa al medio (Maturana y Varela 1995).

${ }^{8}$ El cerebro es una gran concentración de neuronas que forma parte de la red neuronal del sistema nervioso. Esta cefalización es una característica de los mamíferos, que no presentan otros animales en los que el sistema nervioso está distribuido en todo el cuerpo como una cuerda nerviosa -los gusanos, por ejemplo- (Maturana y Varela 1995).

${ }^{9}$ Los péptidos son compuestos nitrogenados formados por la unión de dos o varios aminoácidos, con presencia de CONH en sus enlaces (Capra 1998).

${ }^{10}$ Esto es así, porque el estómago contiene tantas o más células nerviosas que la médula espinal y produce más neurotransmisiones hacia arriba de las que recibe hacia abajo, desde el cerebro mental. El sistema nervioso abdominal condiciona, por tanto, en complementación con el cerebro, más pensamientos, actitudes y emociones de lo que hasta ahora podría haberse imaginado a nivel científico, aunque a nivel del vulgo todos sabemos, desde siempre, que nadie puede pensar cuando el estómago está indispuesto (Arispe 2008). 
La conexión a través de los péptidos hace que nuestra actividad mental esté impregnada de emociones. Los péptidos son su manifestación bioquímica y operan alterando el comportamiento y el estado de ánimo. Los órganos sensoriales y el cerebro están unidos por péptidos que se alojan en los puntos nodales del sistema nervioso central. También los péptidos abundan en los intestinos, donde sentimos frecuentemente muchas emociones bajo la forma de un vuelco de estómago. También está cargado de péptidos el sistema límbico, que tradicionalmente fue identificado por la neurociencia como el área cerebral donde radicaban exclusivamente las emociones. Se puede afirmar en consecuencia que la cognición no es un fenómeno exclusivamente mental: el ser-sentir-hacer-saber son una y la misma cosa.

\section{Unidad sujeto-objeto}

La concepción de autopoiesis y clausura operacional (producirse a sí mismo y en círculo cerrado) de Maturana y Varela implica que no existe un mundo objetivo, separado e independiente del sujeto. Como deriva de las explicaciones precedentes, entre sujeto y objeto existen interferencias mutuas que más que relaciones causa-efecto son procesos coexistentes (Navarro s/f.). En las células, en el sistema nervioso y en los organismos vivos el proceso cognitivo implica la formación de círculos cerrados (autoreflexivos) de actividad que desencadenan conexiones y efectos recíprocos entre los componentes del sistema, de tal manera que no es posible identificar dónde se inicia y donde culmina el proceso (Varela; 1988). “Al intentar conocer el conocer [...] no sabemos dónde ubicar el punto de partida: ¿fuera, adentro? ¿El mundo, la mente?” (Maturana y Varela 1995:162). Ello significa que "dos planos se confunden en uno sólo y a pesar de todo siguen siendo diferenciables” (Varela 1988:57). Esta apreciación es coincidente con la teoría de la unidad, cuando asevera que la realidad es vibración excéntrica y concéntrica en movimientos no lineales, sino circunferenciales y/o espirales, que dan la ilusión del retorno cíclico, pero que en realidad son un desarrollo en espiral, en planos superpuestos diferentes en la forma pero semejantes en el fondo (Gonzáles e Illescas 2002).

La unidad material sujeto-objeto o sujeto-mundo queda expresada en palabras de Varela cuando dice: "No podemos salir del mundo determinado por nuestro cuerpo y nuestro sistema nervioso" (Varela 1988: 60), y "la mente y el mundo emergen juntos" (Varela, cit.por Capra 1998: 279). "La experiencia de cualquier cosa allá afuera es validada de una manera particular por la estructura humana que hace posible «la cosa» que surge en la descripción” (Maturana y Varela 1995:13). Coincidentemente, en la teoría de la unidad no existe ni objeto ni sujeto. Se podría decir que el sujeto no está fuera del objeto, sino dentro de él. El sujeto se convierte en el objeto y éste se hace el sujeto (Gonzáles e Illescas 2003).

Esta visión hace obvio el fracaso de las reformas pedagógicas que fueron formuladas desde la óptica constructivista. Efectivamente, la expe- 
riencia ha demostrado que no generaron aprendizajes de mejor calidad, y ello se debe a que, al no romper con la contradicción sujeto-objeto, no se constituyeron en una alternativa real frente a las limitaciones del positivismo conductista, cuya esencia dicotómica siguieron reproduciendo. Si bien ambos paradigmas pedagógicos se enfrentaron en lo epistemológico ${ }^{11}$ : el conductivismo pone énfasis en el objeto ${ }^{12}$, el constructivismo, en el sujeto $^{13}$, están unificadas en lo ontológico, pues separan al sujeto del objeto. De ese modo, la realidad, eso que el sujeto tiene que "aprehender", sigue estando allá afuera -sea para reproducirla objetivamente o para reconstruirla subjetivamente- y no tiene inteligencia en sí misma. En forma concomitante, el docente, en un caso transmite, en otro, facilita, pero siempre es el que sabe, y el alumno, el que no sabe. Ambos procesos instrumentan la razón -memorística, el uno; hipotético-deductiva, el otro- como única potencia del conocimiento humano.

Para la sabiduría originaria, que concebía (y aún lo hace) la totalidad de la realidad, incluida en ella el hombre, como una unidad entrelazada, donde nada está separado, no se trata de "aprehender", sino de ser la realidad misma en su unidad. En términos del amauta inca José Illescas:

El proceso de "aprehender" a la Pacha ${ }^{14}$ [es un proceso de] Ser-Estar siendo La Unidad con la Pacha [y es] totalmente diferente a la forma de como aprehenden la realidad las sociedades y culturas antropocéntricas de La No Unidad. (Gonzáles e Illescas 2002: 139).

\section{De ese modo:}

Las abuelas-abuelos originarios ancestrales nunca consideraron al individuo fuera de la realidad, sino dentro de ella, SIENDO con ella la realidad misma, [...] por lo que nunca se podía dar la distancia o separación entre lo que occidentalmente se denomina sujeto-objeto, ni mucho menos se podía establecer una relación cognoscente, cuando en

\footnotetext{
${ }^{11}$ La Teoría del Conocimiento explica este fenómeno como conformado por tres elementos: 1) sujeto, 2) objeto (realidad) y, entre ellos, 3) la relación cognoscente. La función del sujeto es aprehender el objeto. Según se ponga el acento en uno u otro elemento, se derivan distintas corrientes: el objetivismo afirma que el objeto determina al sujeto; el subjetivismo sostiene lo contrario

${ }^{12}$ Los objetos son algo dado cuya estructura es reconstruida por la conciencia cognoscente, de modo que el sujeto reproduce, es decir, toma las propiedades del objeto.

${ }^{13}$ El subjetivismo constuctivista considera que, lejos de que el aprendizaje sea una reproducción exacta de la realidad, es una construcción; es decir, el alumno ejerce una acción estructurante sobre el objeto de conocimiento, transformándolo, al otorgarle significado.

${ }^{14}$ Dice Illescas que la Pacha es la totalidad de la realidad, que excede con mucho a la concepción occidental de Universo, ya que éste es sólo un elemento dentro de la realidad total.
} 
esencia todo está combinado e intracombinado en el serestar siendo de la Pacha. (Ibíd: 143).

Si hubiera que hablar de sujeto y objeto, podría decirse que: "El individuo-individualidad ancestral originario era "sujeto-objeto-relación cognoscente" al mismo tiempo. Se hallaba en su estar-hacer "sumergido" en la realidad misma de la Pacha [...]” (Ibíd.)

La unidad sujeto-objeto cambia el problema de la verdad. Desde el momento en que cada uno alumbra desde su estructura interna su propio mundo, nadie debe pretender ser dueño de la verdad. "Nuestras certidumbres no son prueba de verdad, como si el mundo que cada uno ve fuese el mundo y no un mundo que traemos a la mano con otros" (Maturana y Varela 1995: 162). "Cada sistema construye su propio y distinto mundo de acuerdo con su propia y distinta estructura” (Capra 1998:279).

En la teoría de la unidad, nos dice el amauta Illescas, no existe el problema filosófico de la verdad; no hay lo verdadero y lo falso. La realidad es UNA unidad de energía vibracional dentro de cada Uno-Todo; se concentra en cada elemento y cada uno reproduce al todo en su forma, tamaño y densidad de energía concreta. Siendo sí mismo, contiene la totalidad; es la realidad misma en una diferente-semejante forma-fondo. Contiene las características de la realidad, sin ningún antropocentrismo, con su propia y diferente-semejante frecuencia vibracional. Desde su diferencia, cada ser capta lo que puede captar de la realidad; capta lo que es común o semejante, y tiene una percepción de su propia diferencia. De ese modo, cada ser de la realidad, en su propio espacio-tiempo, en su propia existencia, posee su verdad, que resulta de reproducir la realidad en su propia individualidad diferente-semejante. Existirían, por tanto, infinitas verdades, como infinitos seres, con sus existencias concretas, en la totalidad de la realidad, así como la verdad de la realidad total, existiendo en su propio espacio-tiempo (Mazorco 2008).

\section{Las limitaciones de la racionalidad}

La totalidad del sistema de vida occidental -caracterizado por la separación o no unidad entre el ser humano y la totalidad de la realidad-, así como su subsistema educativo, limitan las potencialidades del individuo y configuran, a lo largo de la educación primaria, secundaria y terciaria, un proceso que, al exclusivizar lo lógico, lo deductivo e inductivo, termina linealizando la racionalidad y destruyendo el potencial total (que incluye la racionalidad, pero no en exclusiva) del ser humano. Para el amauta José Illescas, la degradación del proceso educativo deviene del mismo concepto de la Pedagogía como "disciplina de domesticación y destrucción del potencial total de la condición humana" (Gonzáles e Illescas 2003: 17), que quiebra "las condiciones y potencias finitas-infinitas de la niñez" (Ibíd.: 19). De ese modo, el proceso educativo impide al individuo: 
[...] el empleo de todo su potencial infinito-finito [al] poner énfasis en la razón y el pensamiento, [así] como al acentuar sólo la diferencia de la dimensión de lo humano integral, dejando de lado su semejanza. [Por eso] en la No Unidad el niño y la niña pierden en su mágica edad la capacidad de combinar y de intracombinar, y de combinarse como intracombinarse con la Realidad (Ibíd.: 32).

Al centrar toda la posibilidad de conocimiento en la razón, el modelo racionalista del conocimiento occidental reduce esta potencialidad, pues no la integra (no la combina-intracombina) con las otras potencias de lo humano integral: "los instintos, percepciones, sensaciones, sentimientos, deseos, sueños, imaginaciones, visiones, intuiciones, voliciones, retroproyecciones, proyecciones, automutaciones, pensamientos, haceres, comunicaciones y desplazamientos inter e intra-dimensionales ...” (Gonzáles e Illescas 2002: 143), y, de esa manera, la desarrolla a niveles insignificantes.

Para que el ser humano logre la plenitud de sus potencialidades, es necesario un nuevo paradigma ontológico de unidad entre el ser humano y la realidad, que simultáneamente desenrolle una epistemología de unidad sujeto-objeto en el aspecto gnoseológico, y de unidad entre lo racional y lo no racional en el ser humano. En esta transformación paradigmática es necesario que el ser humano:

[...] además de desenrollar el potencial neurológico de los dos hemisferios cerebrales, logre desenvolver la totalidad del cerebro digestivo, endocrino, inmunológico y todos los cerebros de cada una de las células de su propio cuerpo en unidad con toda la Totalidad (Ibíd.: 33).

El otro aporte científico a la comprensión de una nueva epistemología no racionalista proviene del antropólogo francés Jeremy Narby (1997), quien sustenta la tesis del amauta Illescas acerca de que el conocimiento está en los genes. En su investigación de campo con poblaciones amazónicas peruanas pudo comprobar que los chamanes realizan sus prácticas de sabiduría a partir diferentes técnicas que les permiten entrar en estados de conciencia no racionales, en los cuales acceden a la información que ellos contienen en su ADN celular. Esta información se manifiesta en forma de emisiones fotónicas u ondas visibles que expresan en imágenes y palabras el conocimiento guardado en la memoria histórica de los genes de toda la humanidad. Más aún, Narby sostiene que el ADN de toda la naturaleza es capaz de esa comunicación y, de hecho, los chamanes hablan de esa manera con los seres naturales; es de esa manera cómo han adquirido todo su saber médico y botánico.

Esto es así porque, manifiesta el amauta Illescas, al activar el ADNARN, con diversas técnicas, cambia su frecuencia vibracional para ponerse a tono con la vibración de la totalidad. Es como encender la radio o la TV y captar la frecuencia de onda que nos trae los sonidos e imágenes de otra 
dimensión de la multidimensionalidad de la realidad que no vemos en el estado normal de seres separados de la realidad, pero que contenemos, y despierta con estas experiencias, manifestándose en forma de visiones y sueños. Es decir que, para captar la frecuencia de onda de la realidad, el "sujeto" tiene que poner su propia onda en la misma frecuencia con que vibra el “objeto”; de ese modo, tú eres el objeto, lo contienes (Mazorco 2008).

El problema es, menciona Narby, que esta hipótesis actualmente no es recibible por la biología institucional, porque infringe los presupuestos de la disciplina, cuya gran limitación es considerar que la naturaleza no tiene inteligencia ni sabiduría y que el ADN es apenas un ácido desoxyrribonucleico, es decir, un químico inerte. Aunque se toma en cuenta que el ADN es un lenguaje que contiene la información de la vida, no se lo considera, en sí mismo, viviente ni consciente.

\section{La propuesta educativa de la Unidad}

\section{Dice el amauta Illescas:}

La “educación originaria” tiene una estructura completamente diferenciada de la educación que desarrolló, desarrolla y desarrollará la sociedad, cultura y civilización occidental-cristiana” (Gonzáles e Illescas 2002: 21).

Es una educación no antropocéntrica que se orienta al desenvolvimiento del individuo equilibrado, complementario y consensual, que no pierde su identidad. En este proceso, el individuo realizaba su unidad vivencial, que superaba la sola "aprehensión" de la realidad, de modo de conservar la Unidad con la Pacha y la unidad de cada uno en su diferenciasemejanza (Gonzáles e Illescas 2002).

La educación en la civilización de la no unidad impone verticalmente pensamientos, percepciones y prácticas. En las aulas o "jaulas” se mata la energía de lo humano y con ello toda su creatividad. No se deja fluir el potencial total que los niños traen consigo al nacer -pensamientos, ideas, deseos, voluntades, sueños, imaginaciones, intuiciones, instintos, racionalidades-, el cual es bloqueado a partir de las prácticas docentes, no importa a cual teoría del aprendizaje respondan (Gonzáles e Illescas 2003).

En el conductismo, el bloqueo vendrá de considerar la mente del niño como una tabula rasa que tiene que ser llenada a través del puro uso de la memoria. En el constructivismo endogenista piagetiano se estimulará exclusivamente los procesos mentales (lo interno) para ampliar la capacidad de pensar lógicamente. De ese modo, cuando el niño haya "evolucionando" su desarrollo cognitivo y pueda razonar en forma hipotéticodeductiva, según Piaget a los 9-10 años, ya habrá sido amputado de todas las potencias no racionales y habrá "involucionado", pues habrá perdido su condición de ser humano integral. El evolucionismo piagetiano es no sólo 
la expresión de la involución de lo humano integral; sustenta también un racismo eurocéntrico que niega a los niños del tercer mundo el potencial de racionalidad que poseen los del primer mundo. Si bien esto puede hacerse patente en las pruebas internacionales de aptitudes intelectuales, éstas, de ninguna manera, se atreverían a medir cuánto de potencial total aún mantienen los niños que no han sido adoctrinados bajo la amputación racionalista del primer mundo.

La concepción constructivista externalista de Vygotsky concibe que es la interacción social (lo exógeno) la que contribuye al desarrollo cognitivo $^{15}$, al permitir que la persona interiorice los conceptos, destrezas, prácticas, valores, costumbres y normas que caracterizan una cultura determinada ${ }^{16}$. Esta posición ha sido criticada por los humanistas, aduciendo que la internalización no pasa de ser una transferencia instruccional y reproductivista (conductista) que bloquea el desarrollo de la propia identidad del educando. Ellos abogan por una educación que permita desarrollar la integralidad de lo humano: su intelecto y su intuición, ya que: "En tanto función psicológica, como la sensación, el sentimiento o el pensamiento, la intuición es una forma de alcanzar el conocimiento" (Rogers y Freiberg 1996: 71). Si bien esta teoría es un avance con respecto al racionalismo constructivista, sus límites están dados por su condición antropocéntrica, con lo cual, a más de conceder importancia al cerebro derecho, tiene demasiadas restricciones para encarar el cambio ontológico que permita al ser humano sentirse también un ser natural, cósmico y total, y con ello despertar sus infinitas-finitas potencias, además de su racionalidad e intuición. Fruto de ello, el humanismo tiene un sesgo dicotómico de centramiento en el alumno, que debe ser superado, al decir de Gonzáles e Illescas (2003), a partir de una pedagogía centrada en el equilibrio, la complementariedad y el consenso entre educador y educando, en el marco del mutuo respeto de sus respectivas identidades.

Romper la dicotomía sujeto-objeto, mente-mundo hace necesario todavía un paso más: resolver la contradicción entre lo interno y lo externo, y dejar de ver al mundo "allá afuera”, como perciben todavía las teorías educativas que estamos analizando. La teoría de la unidad nos ayuda a superar esta limitación. La combinación-intracombinación parecería

\footnotetext{
${ }^{15}$ Para la psicología genético-dialéctica de Vygotsky, la separación mente-cuerpo y sujetoobjeto queda expresada en la dicotomía sensación-percepción y en la visualización de una conciencia social (un mundo de conceptos e ideas) externa al sujeto, que configura, por internalización, los esquemas mentales del individuo. Según esta teoría la sensación es una función psicológica natural que capta los estímulos externos, y la percepción es una función psicológica superior y privativa del ser humano que, mediante la contrastación de los estímulos sensoriales con los esquemas mentales, crea los contenidos mentales (la conciencia o pensamiento) de la realidad (Stover y Crespo s/f).

${ }^{16}$ Para diferenciarse del conductismo, este tipo de constructivismo sugiere que, lejos de la típica transmisión, la función ideal del maestro es mediar, planificando las actividades de aprendizaje que mejor contribuyan a la autoestructuración del conocimiento del educando.
} 
asociarse con externalidad-internalidad -dicen los filósofos de la unidad-, pero no es así, pues no hay dicotomía externo-interno. Lo externo e interno son una unidad de materia-energía donde la aparente diferencia y separación la establece el individuo, ya que la realidad es UNA materia-energía que se concentra-desconcentra en cada elemento. Lo externo y lo interno son una unidad inseparable por la cual cada uno se desenvuelve en cierta forma y fondo desde sus propias energías o fuerzas internas que transforman para sí y en sí a las energías externas, de manera que lo externo se combina o influencia en lo interno del uno, sólo si lo externo se intracombina con lo interno, o pasa a través de lo interno del UNO-TODO (Gonzáles e Illescas 2002).

El fútil debate constructivista entre lo exógeno y lo endógeno queda superado desde la teoría de la unidad al decir que:

En la "educación ancestral” el individuo, desde antes de ser fecundado, durante su gestación en el vientre materno, durante el nacimiento y en el desarrollo del proceso vital, así como durante su existencia como «muerto», es apreciado y considerado como la unidad que concentra la totalidad social-cultural-civilizatoria y que recibe todo el apoyo de las mismas, y que éstas (sociedad-cultura-civilización), a la vez, reciben del Individuo el logro de todo su pleno desarrollo individual (Gonzáles e Illescas 2002:67).

Como bien dice Maturana, no hay un mundo allá afuera (objetivo) que uno capta y se lo mete en la cabeza (o se representa). Por la unidad de lo externo y lo interno no se capta la realidad, sino que cada uno es-sientehace-sabe la realidad según su propia individualidad, con el sello de su identidad de semejante-diferente Por ejemplo, uno no está metido en el agua para representarse el agua, sino que se siente el agua. Uno no sólo está empapado externamente por el agua, sino transversalizado o permeabilizado totalmente por el agua. Somos agua y no agua al mismo tiempo (Gonzáles e Illescas 2003).

La teoría de la unidad hombre-naturaleza nos acerca al desenvolvimiento del pleno potencial de lo humano, proporcionándonos una propuesta educativa elaborada por Gonzáles e Illescas (2003), que involucra la autodeterminación del niño y del maestro que decidan asumir un proceso autoeducativo tendiente a cancelar la domesticación y la destrucción del potencial total del ser humano realizadas por la pedagogía.

La propuesta del amauta Illescas es asumir un proceso individual de auto-educación, de modo que el educando deje de ser un educando, un objeto de educación, y se asuma como individuo autodeterminado. Ello involucra una auto-reforma en aula, que busca el desenrollamiento de la integralidad humana, natural y cósmica en la niña y en el niño, lo cual requiere cancelar las contradicciones entre educador-educando, entre enseñanza-aprendizaje, entre teoría y práctica, entre orden-caos, entre raciona- 
lidad e irracionalidad, entre principio-fin, entre causa y efecto, entre medios y fines, entre problema y resultados, entre método y contenido, entre método-contenido y objetivos, entre evaluación y resultados, entre competencias por áreas y totalidad, entre escuela y el hogar, entre lo inmediato y lo mediato, entre lo interno y lo externo, entre lo masculino y lo femenino, entre la cultura del educador y la cultura del educando, entre el individuo y la familia-sociedad-cultura-civilización-humanidad, entre el Uno-Todo y el Todo-Uno.

Muy lejos de la propuesta racista y racionalista de la psicología evolutiva, los niños de temprana edad ya tienen su identidad, de modo que el maestro en el aula y los padres en el hogar tienen que ayudar a desenvolverla, en vez de castrarla en nombre de la socialización mediada por la educación. Los niños contienen de adultos, tanto como los adultos contienen en sí al niño que fueron y que aún siguen siendo. De ese modo, la propuesta de la unidad concibe que los niños son maestros de sus docentes, en una relación en la que el educando es educador, y el educador, educando.

En la temprana edad en que ingresan al colegio, los niños poseen despiertas sus potencias integrales; es tarea del docente de nuevo tipo facilitar que ellos desaten su autoproceso de desenvolvimiento integral, antes que dormir sus potencias por el incentivo de la exclusiva racionalidad. Eso no significa, dice Illescas, que no pueda optar por trasmitir y construir conocimientos y acumularlos, en el marco del proceso instructivo de la no unidad, para luego desacumularlos.

¿Qué debe hacer el docente? "Pues, manifiestan Gonzáles e Illescas (2003: 18), dejar fluir, dejar desenvolverse esa corriente de indisciplina; co-orientarlos a que logren sentir-saber el proceso unitario del desobedecer y del obedecer, de la indisciplina y de la disciplina, de caos y del orden, de la construcción y de la destrucción, de la responsabilidad y la irresponsabilidad, del sentimiento y del pensamiento, de la unidad y de la no unidad, del elemento y del conjunto, del femenino y del masculino, del individuo y de la totalidad, de lo humano con el ser de la realidad total. Además, co-conducirlos a desenvolverse con autonomía en su diferencia-semejanza, en el sentimiento-sabiduría del consenso, del equilibrio, de la complementariedad, de la complementación y el respeto a la identidad de cualquier Uno-TodoTodo-Uno".

Se trata de transformar el proceso de enseñanza-aprendizaje para "realizar no sólo la representación de lo que se está aprendiendo, sino para vivir la representación en el objeto mismo: ser el objeto mismo que se aprehende. Así se logrará que la niña y el niño sientan y sepan la realidad total en su unidad y desenvuelvan todo su potencial finito e infinito con toda su diferencia-semejanza, por lo que podrán escribir y hacer todo lo manual con las dos manos, emplear los dos pies, leer en todos los sentidos, calcular sin ayuda manual de papel y lápiz o calculadoras, ver con ambos ojos, escuchar con ambos oídos, realizar esfuerzos físicos y psicológicos no comunes, ejecutar innovaciones y no reproducciones, desenvolver sentimien- 
tos de unidad con todos los otros diferentes-semejantes, sin excepción alguna. Y, sin duda, muchas otras actividades no comunes” (Ibíd.).

El docente tiene que autoexigirse lo mismo que le exige al educando. Además de desenrollar el potencial neurológico de su dos macro hemisferios cerebrales, sostienen Gonzáles e Illescas (2003), deberá desenvolver la totalidad del cerebro digestivo, endocrino e inmunológico, y todos los cerebros de cada una de las células de su propio cuerpo en unidad con toda la totalidad.

Es muy difícil que una educación autónoma y autodeterminante del individuo sea aceptada a nivel oficial; para ello, deberían primero cambiar las condiciones del sistema que vuelven a las escuelas y a su pedagogía instrumentos de manipulación de individuos para volverlos dóciles a la reproducción del sistema. Tampoco la propuesta de la autoeducación puede ser un proceso masificado, porque devendría en adoctrinamiento ideológico. No se trata de elaborar una red curricular que nos de como resultados promociones seriadas de un tipo humano homogenizado, ya que esto no respeta la diferencia-semejanza de cada uno y no permite desenrollar todo el potencial racional y no racional de los niños (Ibíd.).

Por tanto, la reforma que proponemos tiene que asumirse a nivel extra oficial, aún dentro de la educación formal oficial, en el aula, y complementariamente en el hogar, en un proceso de estar y no estar en el sistema educativo y civilizacional de la no unidad, con el sentimiento-pensamiento claro y preciso de que la actual educación y pedagogía son y serán instrumentos de dominación y opresión social, cultural e ideológica, que separan a los niños de la realidad y los predisponen a desarrollar su condición de futuro esclavo del sistema que los domina.

Este proceso es más fácil con los niños, pues ellos tienen más aptitud para sentir que no están en el sistema; por eso se rebelan a todo lo que es educación, en tanto ésta busca disciplinarlos y domesticarlos, haciéndoles perder la capacidad de combinarse e intracombinarse con la realidad. Sin embargo, este proceso no está negado al adulto que sienta y piense la necesidad del auto-cambio y quiera desenvolver el pleno potencial cognitivo que duerme en sus sentimientos, en su imaginación, en su intuición, en su instinto, en su voluntad, en sus deseos, en su pensamiento, en la retro-proyección, en la proyección, en los sueños, en las auto-sensaciones, en las auto-percepciones, en las extensiones de existencia en la totalidad del ser (Ibíd.).

El desafío está planteado: es necesario un cambio epistemológico; pero para no caer en el nada cambia que nos trajo el constructivismo es necesario superar las limitaciones del modelo civilizacional antropocéntrico: sólo superando el antropocentrismo (este es el cambio ontológico) el individuo podrá sentirse humano al mismo tiempo que árbol, estrella, río, luciérnaga u oso, y aprenderá de ellos lo que ellos tengan que decirle. Para escucharlos y sentirlos deberá abrir mucho más que sus sentidos y su men- 
te; tendrá que despertar todas potencias finitas e infinitas que duermen en sus genes desde que el ser humano integral originario fue domesticado por la instrumentalización racional de la educación y la comunicación del sistema de la no unidad. 


\section{Bibliografía}

Arispe, Sergio; Mazorco, Graciela y Rivera, Maya (2008), “Dicotomías étnicas y filosóficas en la lucha por la descolonización” en Polis. Revista de la Universidad Bolivariana $\mathrm{N}^{\circ}$ 18, Universidad Bolivariana, Santiago.

Capra, Fritjof (1998), La trama de la vida. Una perspectiva de los sistemas vivos, Editorial Anagrama S.A. Barcelona.

Foucault, Michel (1980), Microfísica del poder. $2^{\circ}$ ed, Las Ediciones de la Piqueta, Madrid.

Gonzáles, Tatiana e Illescas, José (2002), Acerca de la Ontología, Gnoseología y Epistemología de lo Humano Integral, Ediciones Tukuy Riqch’arina, Santa Cruz, Bolivia.

Idem (2003), Acerca de algunas breves consideraciones sobre la Educación, la Interculturalidad, la Intraculturalidad, Lo Humano Integral Originario, lo Andino y la Sociedad-Cultura-Civilización de la Unidad, Ediciones Tukuy Riqch’arina, Cochabamba.

Idem (2003), Acerca de la descomposición y agonía de lo que hemos venido denominando educación y del surgimiento de la posibilidad de los procesos de sentir-pensar el ser y la autonomía en el cotidiano individual y colectivo, Ediciones Tukuy Riqch’arina, Cochabamba.

Maturana, Humberto (1992), Emociones y lenguaje en Educación y Política. $6^{\circ}$ ed, Ediciones Pedagógicas Chilenas S.A., Santiago.

Maturana, Humberto y Varela, Francisco (1995), El árbol del conocimiento: Las bases biológicas del entendimiento humano. $12^{\circ} \mathrm{ed}$, Editorial Universitaria, Santiago.

Mazorco, Graciela (2003), Educación y Saber Andino: Una mirada a la educación superior desde el sentimiento de la unidad, PROMEC-Universidad Mayor De San Simón, Cochabamba.

Idem (2008), Filosofía, Ciencia y Saber Andino: Bases ontológicas, gnoseológicas y epistemológicas de la inter e intraculturalidad, $2^{\circ}$ ed. Editorial Universidad Bolivariana, Santiago.

Narby, Jeremy (1997), La serpiente cósmica: el ADN y los orígenes del saber, Takiwasi y Racimos de Ungurahui, Lima-Perú.

Navarro, Pablo (s/f), “El fenómeno de la complejidad social humana” en: www.netcom.es/pnavarro/Publicaciones/ComplejidadSocial.html (consultado el 02-10-06). 
Polis, Revista de la Universidad Bolivariana, Volumen 9, $N^{\circ}$ 25, 2010

Rogers, Carl y Freiberg, Jerome (1996), Libertad y creatividad en la educación. Paidós Educador $3^{\circ}$ ed., Barcelona.

Stover, J. y Crespo, Boris. (s/f), “La teoría del conocimiento”. Apuntes para el Módulo II-Unidad II de la Licenciatura semipresencial en Ciencias de la Educación. Universidad Americana.

Thompson, William (1992), “Las implicaciones culturales de la nueva biología” en Lovelock, J. y otros. Gaia: Implicaciones de la nueva biología. $2^{\circ}$ ed., Editorial Kairós, Barcelona.

Varela, Francisco (1988), “El círculo creativo: esbozo histórico-natural de la reflexividad” en Suplemento Anthropos (22): 56-61, octubre 1990. 